\title{
Cultivated land utilization index vis-a-vis cropping intensity for crop diversification and water resource management in Odisha, India
}

\author{
P. S. Brahmanand ${ }^{1, *}$, Biswaranjan Behera ${ }^{1}$, Shivendra Kumar Srivastava ${ }^{2}$, \\ R. B. Singandhupe ${ }^{3}$ and A. Mishra ${ }^{1}$ \\ ${ }^{1}$ ICAR-Indian Institute of Water Management, Bhubaneswar 751023 , India \\ ${ }^{2}$ ICAR-National Institute of Agricultural Economics and Policy Research, New Delhi 110 012, India \\ ${ }^{3}$ ICAR-Central Institute for Cotton Research, Nagpur 440 010, India
}

The cultivated land utilization index (CLUI) for all the districts of Odisha, India during 2013-14 was estimated in this study. The average state CLUI value $(\mathbf{0 . 5 8 5})$ indicated the scope of improving resource utilization, though $67 \%$ of the net cropped area is sown twice. All the districts of the state were classified under four scenarios with various combinations of cropping intensity and CLUI. Growing long-duration crop varieties under conditions of ample water availability and, more short-duration less water-requiring crops under limited water supply will improve resource utilization. The results pave the way for analysis of CLUI at a national level for efficient resource utilization by formulating cropping patterns based on water availability.

Keywords: Cultivated land utilization index, cropping intensity, crop diversification, water resource management, water availability.

AMIDST burgeoning population and transitions in the economy, agriculture is accorded high priority to sustain food and nutritional security and overall economic development in our nation. Apart from a source of food, agriculture provides livelihood to $44.5 \%$ of India's workforce. During 2018-19, India produced 285 million tonnes (Mt) of food grains from the net cultivated area of about 140 million hectare $(\mathrm{M} \mathrm{ha})^{1}$. It is projected that in 2050 the country would require about $350 \mathrm{Mt}$ of food grains to feed the growing population ${ }^{2}$. Further, food consumption pattern is changing towards high-value agricultural commodities which are more resources-intensive. Against the rising demand and changing food consumption pattern, the natural resources supporting agricultural production, such as soil and water, have been shrinking over time. Therefore, food grain production needs to be increased without disturbing the sustainability of natural resources. Among several measures, realigning existing cropping

\footnotetext{
*For correspondence. (e-mail: psbanand@yahoo.com)
}

patterns with the availability of natural resources is given high priority. Often, it is suggested to diversify cropping pattern from high water-requiring crops to less waterrequiring crops based on analysis of crop and water profile at the regional level ${ }^{3}$.

Land, water and solar radiation are the core natural resources essential for successful crop production ${ }^{4,5}$. Efficient use of these resources in crop production is the need of the hour to meet the food demand of the everincreasing population in India. In this context, cropping intensity (ratio of gross cropped area to net cropped area) is a widely used indicator of land utilization for future agricultural water management and crop diversification planning. The cropping intensity is the ratio between gross cropped area and net cropped area, and hence it gives an idea about utilization efficiency of the land ${ }^{6}$. However, the interpretation of cropping intensity alone may not provide a complete picture of land-use efficiency, as it does not consider the solar energy harnessing period. For example, if sugarcane with 12 months duration is grown in 2 ha of cultivated land, the cropping intensity would be $100 \%$ only. Whereas in the same piece of land, if a farmer grows rice crop for five months duration followed by green gram crop for two months duration and watermelon for three months duration, the cropping intensity would be $300 \%$. In the former scenario, though sugarcane crop is grown for all 12 months in the year, the cropping intensity is low, i.e. $100 \%$. However, in the latter scenario, though the land is utilized by rice, green gram and watermelon for only ten months in the whole year, the cropping intensity is three times higher than the former scenario. Here, the cropping intensity reflects a part of the real picture neglecting better solar energy harness in the former scenario.

Cropping is a practice of harnessing solar radiation by growing crop plants on a piece of land. The crop plants harness solar energy in the form of carbohydrates through photosynthesis ${ }^{7}$. The crop duration indicates solar energy harnessing period in a year and determines the quantity of carbohydrate fixation and crop productivity. Therefore, 
Table 1. Criteria for categorization of cropping intensity and cultivated land utilization index (CLUI) of Odisha, India

\begin{tabular}{lcccccc}
\hline & & \multicolumn{2}{c}{ Cropping intensity } & & \multicolumn{2}{c}{ CLUI } \\
\cline { 3 - 4 } \cline { 6 - 7 } Category & Sub-category & Short-form & Criteria value & & Short-form & Criteria value \\
\hline \multirow{2}{*}{ Low } & 1 & $I_{l 1}$ & $<140$ & & $U_{l 1}$ & $<0.500$ \\
& 2 & $I_{l 2}$ & $140-165$ & & $U_{l 2}$ & $0.501-0.60$ \\
High & 1 & $I_{h 1}$ & $166-190$ & & $U_{h 1}$ & $0.601-0.70$ \\
& 2 & $I_{h 2}$ & $>190$ & & $U_{h 2}$ & $>0.700$ \\
\hline
\end{tabular}

the percentage of available solar energy harnessed in a region may represent land utilization in a better manner than the cropping intensity alone ${ }^{8}$. Therefore, there is a need for evolving some other indicators in addition to cropping intensity to provide the real picture of land utilization throughout the year. This will help policymakers in taking appropriate decisions on optimization of cropping patterns, keeping the land and water resources under consideration.

The present study proposes to consider cultivated land utilization index (CLUI) along with cropping intensity instead of cropping intensity alone while formulating planning for crop, land and water resource use. CLUI is a ratio between summation of products of crop cultivated area and crop duration, and the product of total crop cultivated area and the total number of days in a year $(365)^{9}$. This index reflects the utilization of available solar energy with an assumption that the solar flux density (amount of solar radiation per unit area per unit time) in a region is uniform throughout the year. However, it does not reflect the intensity of cropping practices and resource use. Therefore, the combination of CLUI, and cropping intensity, may represent the actual land resource use better than the sole CLUI or cropping intensity. Although the concept of CLUI has been used by some researchers for specific target areas/cropping systems ${ }^{10,11}$, a comprehensive analysis at the state level has not been carried out.

This approach of considering both CLUI and cropping intensity would aid in formulating water and agricultural policy at both national and state levels. Further, scenariowise strategies for crop diversification and water resource development and utilization will undoubtedly ensure successful implementation of the prime objectives of the New Agricultural Policy of Odisha, 2020.

\section{Materials and method}

An analysis of land utilization based on scenarios with a different combination of cropping intensity and CLUI was carried out for all the districts of Odisha. In this analysis, all the cultivated crops of the state were classified as rice, other cereals, pulses, oilseeds, vegetables, fibres, spices, sugarcane, tobacco and fruit crops. Data related to gross cropped area, net cropped area, cultivated area under individual crops/crop groups and cropping intensity of all the districts were obtained from the latest available Odisha Agriculture Statistics 2013-14 (ref. 12). The crop species and variety determine the crop duration and hence affect resource use and productivity. With a critical look on the major cultivated crops and their dominant varieties in the state, a standard representative crop duration was taken for a crop/crop group, irrespective of the districts. The assumed cropping duration of different crop/crop groups was 140 days for rainy season rice and 120 days for dry season rice, 120 days for other cereals, 80 days for pulses, 110 days for oilseeds, 160 days for fibres, 110 days for vegetables, 180 days for spices and 365 days for fruit trees. CLUI for all the districts of Odisha was estimated using the following equation

$$
\mathrm{CLUI}=\frac{\sum_{i=1}^{n} a_{i} d_{i}}{A \times 365}
$$

where $i=1,2,3, \ldots, n ; n$ is the total number of crops, $a_{i}$ the area occupied by the $i$ th crop (ha), $d_{i}$ the duration of the $i$ th crop (days) and $A$ is the total cultivated land area available for 365 days (ha).

The cropping intensity and CLUI of all the districts were classified into two categories and four subcategories (Table 1).

The land-use analysis for different districts was carried out under four scenarios having different combinations of cropping intensity and CLUI categories (Table 2).

Water is one of the crucial factors that decides the cropping pattern of a region. Therefore, water availability in different districts of Odisha was considered to develop strategies for improving land utilization under different scenarios. Data on water demand and supply in various districts were collected from the State Irrigation Plan of Odisha $^{13}$. The water supply includes both surface and groundwater resources, whereas water demand includes crop water demand, domestic water demand, livestock water demand and industrial water demand. The balance between water supply and demand in different districts was estimated by subtracting the water demand from the water resource availability. A positive water supplydemand balance (water surplus) in a district was quantified as the amount of water available for providing extra 
Table 2. Scenarios with different combinations of various categories of cropping intensity and CLUI

\begin{tabular}{|c|c|c|c|c|c|}
\hline \multicolumn{2}{|l|}{ Scenario } & \multirow{2}{*}{\multicolumn{4}{|c|}{ Sub-scenarios }} \\
\hline Description & Short-form & & & & \\
\hline High cropping intensity and high CLUI & $I_{h} U_{h}$ & $I_{h 1} U_{h 1}$ & $I_{h 1} U_{h 2}$ & $I_{h 2} U_{h 1}$ & $I_{h 2} U_{h 2}$ \\
\hline Low cropping intensity and high CLUI & $I_{l} U_{h}$ & $I_{l 1} U_{h 1}$ & $I_{l 1} U_{h 2}$ & $I_{l 2} U_{h 1}$ & $I_{l 2} U_{h 2}$ \\
\hline Low cropping intensity and low CLUI & $I_{l} U_{l}$ & $I_{l 1} U_{l 1}$ & $I_{l 1} U_{l 2}$ & $I_{l 2} U_{l 1}$ & $I_{l 2} U_{l 2}$ \\
\hline High cropping intensity and low CLUI & $I_{h} U_{l}$ & $I_{h 1} U_{l 1}$ & $I_{h 1} U_{l 2}$ & $I_{h 2} U_{l 1}$ & $I_{h 2} U_{l 2}$ \\
\hline
\end{tabular}

The short-forms in the sub-scenarios are according to Table 1.

irrigation during the dry season. Here, the dry season includes winter and summer seasons as the state receives majority of its total rainfall between June and October. The utilization efficiencies for surface water and groundwater were assumed to be $50 \%$ and $70 \%$ respectively ${ }^{14}$, to calculate actual surplus water available for irrigation. Besides irrigation, residual soil moisture can also be used during dry season. The residual soil moisture available for dry-season crops in different districts was estimated by taking seasonal potential evapotranspiration $\left(\mathrm{ET}_{0}\right)$ and rainfall into consideration. $\mathrm{ET}_{0}$ is the maximum evapotranspiration that can occur from an optimally grown and well-watered grass reference crop in a region. Therefore, the difference between $\mathrm{ET}_{0}$ and effective rainfall during the rainy season was quantified as the minimum quantity of residual soil moisture available for the dry season. Data on seasonal $\mathrm{ET}_{0}$ and rainfall in different districts of Odisha were taken from the study by Singandhupe and Sethi ${ }^{15}$. During the rainy season, $65 \%$ of rainfall was assumed as effective to take run-off and percolation losses into account ${ }^{16}$. Whereas during dry season, $100 \%$ rainfall was considered to be effective. The difference between $\mathrm{ET}_{0}$ and rainfall was taken as the seasonal crop water requirement gap during dry seasons (eq. (1)). The available residual soil moisture was subtracted from the seasonal crop water requirement gap to estimate the irrigation requirement during dry seasons (eq. (2)). The potential cultivable area that can be brought under cropping by providing extra irrigation during dry season was calculated for the districts having positive water supply-demand balance using eq. (3).

Crop water requirement gap during dry season

$=$ Seasonal potential evapotranspiration $\left(\mathrm{ET}_{0}\right)$

- rainfall

Irrigation requirement during dry seasons

$$
\begin{aligned}
& \text { = Crop water requirement gap } \\
& \text { - residual soil moisture }
\end{aligned}
$$

Potential cropping area during dry seasons

$$
=\frac{\left(\begin{array}{l}
\text { Actual surplus water } \\
\text { available for irrigation }
\end{array}\right)}{\text { Irrigation requirement }} \text {. }
$$

The scenario-wise suitable crop planning strategies based on total available water have been suggested for the dry season to enhance farm income through better utilization of available resources.

\section{Results and discussion}

The CLUI values for different districts of Odisha were calculated and compared with the respective cropping intensity values (Table 3). During 2013-14, the average cropping intensity and CLUI values for the state were $167 \%$ and 0.585 respectively. This indicates that though $67 \%$ of the net cultivated area is sown twice in a year, only $58.5 \%$ of total available solar energy is harnessed. It reflects the scope of improving productivity through better utilization of available solar energy even at the same cropping intensity in the state. There was considerable variation in cropping intensity and CLUI across the districts of the state. The cropping intensity ranged from $133 \%$ (Jharsuguda) to $198 \%$ (Gajapati and Jajpur), and CLUI ranged from 0.489 (Sundaragarh) to 0.742 (Khordha). The difference in the level of cropping intensity and CLUI within a district implies underutilization of available land (when the level of cropping intensity is lower) or solar energy (when the level of CLUI is lower) (Table 3 ).

The surface water resources of Odisha were estimated to be $66.8 \mathrm{BCM}$ compared to the total water demand of $54.66 \mathrm{BCM}$, indicating $12.14 \mathrm{BCM}$ surplus water in the state $^{13}$. However, the water supply and demand distribution was not uniform in Odisha, as it had highest water surplus of $1.68 \mathrm{BCM}$ in Cuttack to highest water deficit of $1.67 \mathrm{BCM}$ in Khordha (Figure 1). The computed reference evapotranspiration $\left(\mathrm{ET}_{0}\right.$; annual evaporative demand) of the state was $1658 \mathrm{~mm}$, whereas total annual water supply through rainfall was $1492.8 \mathrm{~mm}$ (ref. 15). Guhathakurta et al. ${ }^{17}$ reported that the variability of seasonal and annual rainfall of the state during 1989-2018 was $14.9 \%$ and $14.4 \%$ respectively. The seasonal rainfall variability was higher during rainy season $(24.3 \%-$ $32.9 \%$ ). The seasonal rainfall and $\mathrm{ET}_{0}$ of Odisha indicate a water surplus of $106.55 \%$ during rainy season (JuneOctober) and a water deficit of $83.7 \%$ and $76.9 \%$ during the dry season (November-March and April and May respectively $)^{13}$. The surplus water during rainy season can be utilized during dry season through in situ water conservation. 
Table 3. Cropping pattern, gross cultivated area (GCA), cropping intensity (CI) and CLUI of different districts in Odisha

\begin{tabular}{|c|c|c|c|c|c|c|}
\hline \multirow[b]{2}{*}{ District } & \multirow{2}{*}{ 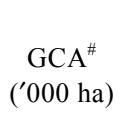 } & \multirow{2}{*}{ Major cropping pattern } & \multicolumn{2}{|c|}{$\%$ of GCA under } & \multirow[b]{2}{*}{$\mathrm{CI}(\%)$} & \multirow[b]{2}{*}{ CLUI } \\
\hline & & & Rainy season & Dry season & & \\
\hline Angul & 301.5 & Rice $(78)$, pulses $(57+46)$, oilseeds $(30) *$, vegetables $(24) *$ & 62 & 30 & 168 & 0.591 \\
\hline Balasore & 322.2 & Rice (195), rice (31) & 63 & 33 & 169 & 0.640 \\
\hline Bargarh & 473.0 & Rice $(241+84)$, pulses $(64+18)$, oilseeds $(23+14)$ & 72 & 27 & 142 & 0.492 \\
\hline Bhadrak & 235.9 & Rice (118), vegetables (87), pulses $(23)^{*}$ & 88 & 18 & 139 & 0.533 \\
\hline Bolangir & 489.4 & Rice $(200)$, pulses $(74+77)$, fibres $(41)$, vegetables $(21+20)$ & 73 & 24 & 168 & 0.576 \\
\hline Boudh & 138.3 & Rice $(66.0)$, pulses $(14+23)$ & 67 & 29 & 163 & 0.566 \\
\hline Cuttack & 303.1 & Rice (118), pulses $(113)^{*}$, vegetables $(22)^{*}$ & 44 & 52 & 193 & 0.657 \\
\hline Deogarh & 108.5 & Rice $(50)$, pulses $(13+10)$ & 68 & 26 & 175 & 0.647 \\
\hline Dhenkanal & 261.4 & Rice $(91.8)$, pulses $(22+49)$, oilseeds $(20+14)$, fruits $(25)$ & 57 & 33 & 195 & 0.736 \\
\hline Gajapati & 150.2 & Rice $(38)$, other cereals $(28)$, pulses $(11+22)$ & 59 & 29 & 198 & 0.655 \\
\hline Ganjam & 704.4 & Rice $(251)$, pulses $(38+213)$, oilseeds $(24+38)$ & 56 & 39 & 181 & 0.561 \\
\hline Jagatsingpur & 177.2 & Rice $(80)$, pulses $(56)^{*}$ & 48 & 48 & 197 & 0.681 \\
\hline Jajpur & 279.5 & Rice $(124)$, pulses $(67)^{*}$, oilseeds $(34) *$, vegetable $(11+13)$ & 54 & 43 & 198 & 0.678 \\
\hline Jharsuguda & 81.0 & Rice (40) & 71 & 22 & 133 & 0.491 \\
\hline Kalahandi & 616.9 & Rice $(209+40)$, pulses $(83+117)$, oilseeds $(15+33)$, fibres $(45)$ & 62 & 35 & 184 & 0.599 \\
\hline Kandhamal & 188.5 & Rice $(46)$, other cereals $(20)$, oilseeds $(14+19)$, pulses $(12+15)$ & 66 & 22 & 176 & 0.666 \\
\hline Kendrapara & 262.6 & Rice $(133)$, pulses $(78)^{*}$, vegetables $(9+14)$ & 56 & 42 & 194 & 0.660 \\
\hline Keonjhar & 393.3 & Rice $(173)$, pulses $(28+46)$, vegetables $(27+23)$, oilseeds $(15+17)$ & 70 & 24 & 161 & 0.559 \\
\hline Khordha & 207.4 & Rice $(97)$, pulses $(55)^{*}$, fruits $(20)$ & 56 & 35 & 192 & 0.742 \\
\hline Koraput & 400.3 & Rice $(112+21)$, other cereals $(101)$, pulses $(16+21)$, oilseeds $(25)$ & 71 & 18 & 147 & 0.494 \\
\hline Malkangiri & 230.8 & Rice $(98)$, oilseeds $(28+19)$ & 70 & 16 & 170 & 0.693 \\
\hline Mayurbhanj & 491.8 & Rice $(301)$, pulses $(32+36)$ & 74 & 19 & 138 & 0.524 \\
\hline Nabarangpur & 289.7 & Rice (146), other cereals (66) & 81 & 12 & 160 & 0.513 \\
\hline Nayagarh & 242.3 & Rice $(101)$, pulses $(10+72)$, fruits $(20)$ & 56 & 36 & 192 & 0.701 \\
\hline Nuapada & 290.8 & Rice $(100)$, pulses $(59+44)$, oilseeds $(22+13)$ & 73 & 24 & 156 & 0.492 \\
\hline Puri & 256.0 & Rice $(103+33)$, pulses $(62)^{*}$, fruits $(23)$ & 42 & 49 & 191 & 0.730 \\
\hline Rayagada & 268.9 & Rice (64), other cereals (39), pulses $(36+21)$, fibres $(28)$ & 73 & 20 & 168 & 0.550 \\
\hline Samabalpur & 273.2 & Rice $(140+22)$, pulses $(28+17)$ & 67 & 26 & 153 & 0.580 \\
\hline Subarnapur & 230.4 & Rice $(109+28)$, pulses $(16+29)$, vegetables $(13+9)$ & 63 & 33 & 190 & 0.672 \\
\hline Sundargarh & 385.6 & Rice $(209)$, pulses $(36+30)$ & 76 & 19 & 136 & 0.489 \\
\hline Odisha & 9054.0 & - & 65 & 29 & 167 & 0.585 \\
\hline
\end{tabular}

Figures within the parentheses $(X)$ indicate $X$ area under a particular crop during rainy season; $(X+Y)$ indicates $X$ area under a crop during rainy season and $Y$ area during dry season (winter and summer seasons); ( )* indicates area under a crop during dry season. ${ }^{\#}$ GCA includes total cultivated area under rainy and dry seasons and area under fruit crops (throughout the year).

Srivastava et al. ${ }^{18}$ developed a run-off-recycling pond $\left(1468 \mathrm{~m}^{3}\right.$ capacity and $900 \mathrm{~m}^{2}$ water area) to store rainwater during the rainy season and use it in the nonmonsoon period for humid plateau region of Eastern India. This pond stored $2574 \mathrm{~m}^{3}$ water per year with a catchment area of 3 ha and command area of 0.95 ha. Sahu et al. ${ }^{19}$ reported $14.3 \%$ to $87.1 \%$ increase in yield of various crops grown during dry season with supplemental irrigation from small farmers' reservoirs in Chhattisgarh. Rathore et $a l^{20}$ developed an in situ rainwater harvesting pond of $750 \mathrm{~m}^{3}$ capacity (0.09 ha area) with microcatchment area of 0.66 ha and command area of 0.33 ha. Rice, soybean, peanut and pigeon pea were grown during rainy season, while chickpea and mustard were grown during dry season. The benefit : cost ratio was maximum $(2.81: 1)$ under soybean-chickpea cropping pattern. Several reports on rainwater harvesting during the rainy season and its use as supplemental irrigation for growing crops during the dry season are available ${ }^{19,20}$. Besides, growing crops throughout the year results in atmospheric cooling and subsequent reduction in evaporation loss, as advective energy from the surrounding fields for evapora- tion loss is minimized ${ }^{21}$. Several researchers have studied the impact of irrigation and surface evapotranspiration and deforestation on climate change and observed substantial fluctuations in climatic parameters when irrigation is provided to different crops, or when forest grassland is converted into vegetation ${ }^{22-26}$. Hence, growing of double crops in a year can change the microclimate of the region and their impact on water productivity and socio-economics of the farmers. Figure 2 shows the potential area that can be brought under cultivation by meeting crop irrigation requirements with supplemental irrigation in water-surplus districts.

Therefore, there is scope for improving resource use efficiency in the state by formulating optimum crop planning based on cropping intensity, CLUI and water availability in different districts. The utilization efficiency of both land and solar energy (cropping intensity and CLUI respectively) can be improved only with unlimited water resources. Under limited water resource, cropping intensity can be improved by shifting cropping pattern from high water-demanding crops to short duration, less waterrequiring crops. CLUI can be improved by growing 


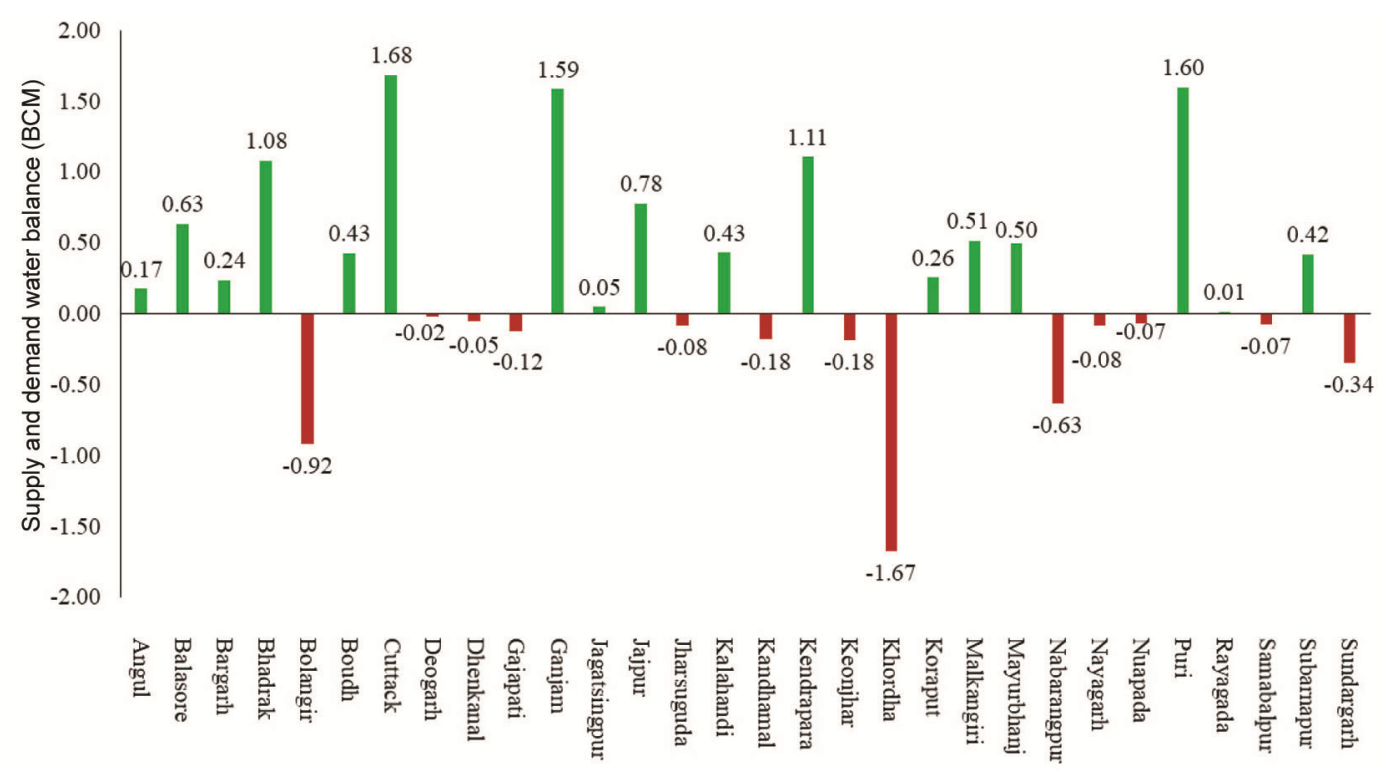

Figure 1. Supply and demand water balance in different districts of Odisha ${ }^{14}$, India.

long-duration varieties of less water-requiring crops under such conditions. The classification of all districts of Odisha under different scenarios having various combinations of cropping intensity and CLUI would provide a better picture of this scope. The districts were classified under four different scenarios, each having four sub-scenarios (Figure 3).

\section{Scenario 1: high cropping intensity and high CLUI $\left(I_{h} U_{h}\right)$}

There were 14 districts under this scenario. The cropping intensity ranged from 169\% (Balasore) to 198\% (Gajapati and Jajpur), whereas CLUI ranged from 0.640 (Balasore) to 0.742 (Khordha) (Figure 3). There is little scope for improving cropping intensity and CLUI in the districts under this scenario. However, diversification of the existing cropping pattern with shifting from water-guzzling crops to less water-requiring crops may result in higher resource-use efficiency. In this scenario, adoption of high-value crops during rabi and summer season coupled with pressurized irrigation system can improve overall crop yield and saving of irrigation water. The field studies conducted on vegetables crops (tomato, brinjal, capsicum), medicinal plants (mint, ashwagandha, safed musali) and both water- and nutrients-exhaustive corps like sugarcane, cotton and banana in different agroclimatic zones of India ${ }^{27-30}$ revealed that there was significant improvement in yield $(3 \%-12.5 \%)$ as well as saving of irrigation water over surface irrigation method $(31 \%$ $37 \%$ ). The districts with reasonable scope of improving cropping intensity and CLUI could be identified from sub-scenario analysis. There were four districts in $I_{h 2} U_{h 2}$, six in $I_{h 2} U_{h 1}$, four in $I_{h 1} U_{h 1}$ and no districts in $I_{h 1} U_{h 2}$ subscenarios.

Under $I_{h 2} U_{h 2}$, out of four districts, Puri had the lowest cropping intensity (191\%), and Nayagarh had the lowest CLUI. The water supply-demand balance was positive for the Puri district only (Figure 1). The estimated potential area that can be brought under cultivation by providing supplemental irrigation during dry seasons in this district was 157,600 ha (Figure 2). In Puri, rice is the dominant crop during rainy season, whereas both rice and pulses are grown in considerable proportion during the dry season (Table 3 ). The cropping intensity and CLUI in this district can further be increased by growing pulses, oilseeds and summer vegetables with supplemental irrigation during the dry season. In Nayagarh, the cropping intensity was higher but CLUI was lower than that in Puri. This might be due to more area under short-duration pulse crops in both rainy and dry seasons in the former compared to the latter (Table 3). The available solar energy and cropping window can be utilized better by growing long-duration varieties of low water-requiring crops in this district.

The districts under $I_{h 2} U_{h 1}$ had lower CLUI compared to those under $I_{h 2} U_{h 2}$ at a similar level of cropping intensity (Figure 3). The CLUI values in this sub-scenario ranged from 0.655 (Gajapati) to 0.681 (Jagatsinghpur). The cropping pattern in the districts reflect considerable proportion of area under short-duration crops like pulses and oilseeds (Table 3). Except for Gajapati, all districts had surplus water for providing supplemental irrigation (Figure 1). In those districts, the cropping area can be extended further during the dry season to increase cropping intensity and CLUI (Figure 2). In Cuttack, 52\% of gross cropped area (GCA) was under dry-season crops, 


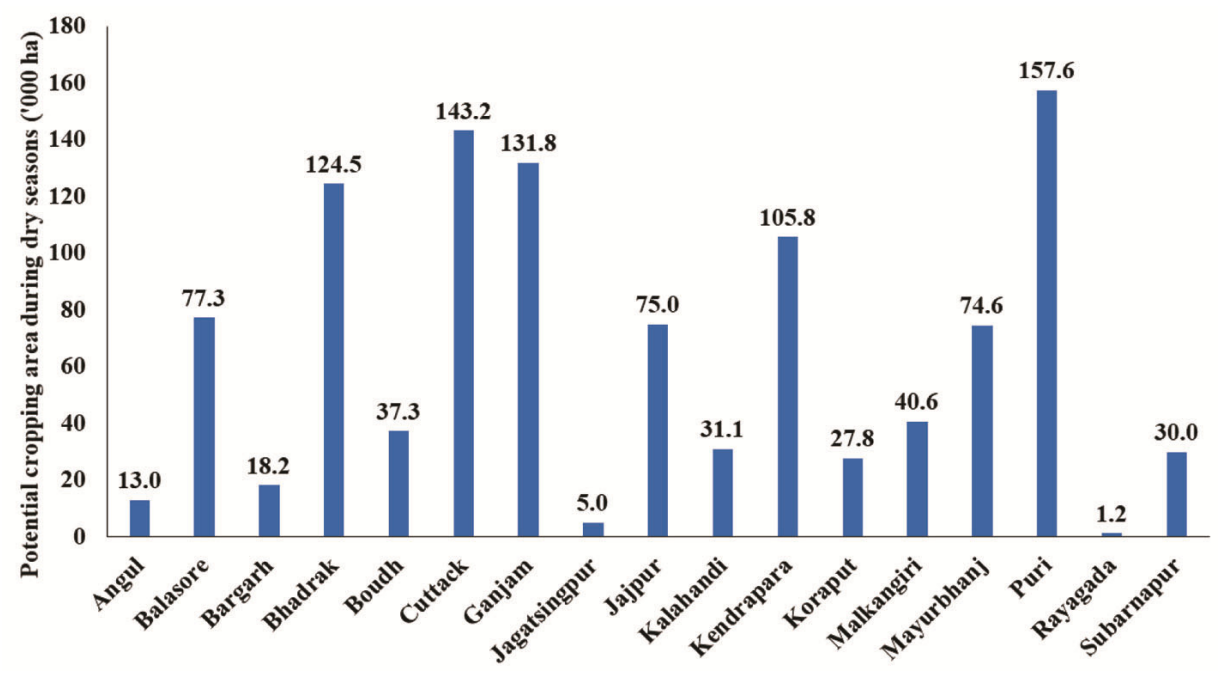

Figure 2. Potential cropping area during the dry season.

which was higher than that in the rainy season (Table 3 ). Therefore, the cropping area can be extended further during both rainy and dry seasons in this district. In Gajapati district, where no supplemental irrigation is available in the dry season, some rice area can be shifted towards growing long-duration varieties of low water-requiring crops such as pulses, oilseeds and vegetables to increase CLUI.

Among the sub-scenarios of the $I_{h} U_{h}$ scenario, the $I_{h 1} U_{h 1}$ included the districts having lower cropping intensity (166\%-190\%) and CLUI (0.601-0.700) (Figure 3). Among the four districts under this sub-scenario, Balasore and Malakanagiri had positive but Kandhamal and Deogarh had negative water supply-demand balance (Figure 1). It is noteworthy to mention that only 33\% and $16 \%$ of GCA was under dry season crops in the earlier two districts respectively, despite surplus water availability. In Balasore and Malkanagiri, the cropping area during dry season can further be extended by 77,300 ha and 40,600 ha respectively, by providing supplemental irrigation (Figure 2). However, in Deogarh and Kandhamal, the cropping intensity and CLUI can be improved by shifting the cropping pattern more towards low water-requiring crops.

\section{Scenario 2: low cropping intensity and high CLUI $\left(I_{l} U_{h}\right)$}

Out of 30 districts of Odisha, none had this combination (Figure 3). Generally, this combination occurs when a longer duration crop is grown in a region. For example, growing sugarcane crop of 12 month duration will result in lower cropping intensity and higher CLUI than that of growing three crops of 3-months duration each in a year. In Odisha, longer-duration crops like sugarcane (12 months), long-duration pigeon pea (6 months), deshi cotton (6-8 months duration) are grown only in small pockets. Though this combination shows inefficient land utilization due to less number of croppings/year, it harnesses the available solar energy more. This combination can improve crop productivity under ample availability of resources.

\section{Scenario 3: low cropping intensity and low CLUI $\left(I_{l} U_{l}\right)$}

There were 11 districts, namely Sambalpur, Keonjhar, Boudh, Nabarangpur, Bhadrak, Mayurbhanj, Jharsuguda, Sundargarh, Bargarh, Koraput and Nuapada under this scenario. The cropping intensity ranged from $133 \%$ (Jharsuguda) to $163 \%$ (Boudh), whereas the CLUI ranged from 0.489 (Sundargarh) to 0.580 (Sambalpur) (Figure 3 ). There is ample scope for improving cropping intensity and CLUI in the districts under this scenario. Out of the 11 districts, only Bargarh, Bhadrak, Boudh, Koraput and Mayurbhanj had positive water supply-demand balance (Figure 1). The contribution of dry-season crops to GCA was considerably lower than that of rainy-season crops in these districts. Therefore, there is considerable scope of improving cropping intensity and CLUI in these districts by bringing more area under cultivation during the dry season. The potential area that can be brought under cultivation during dry season in Bargarh, Bhadrak, Boudh, Koraput and Mayurbhanj is 18,200, 124,500, 37,300, 27,800 and 74,600 ha respectively (Figure 2). Among the districts with surplus water, Bargarh and Koraput had lower CLUI than the others. Therefore, CLUI in these two districts can further be improved by adequately fitting the longer-duration crop varieties in the cropping window. The cropping pattern of the six water-deficit districts, viz. Sambalpur, Keonjhar, Nabarangpur, Jharsuguda, Sundargarh and Nuapada, reflects more area under rice 


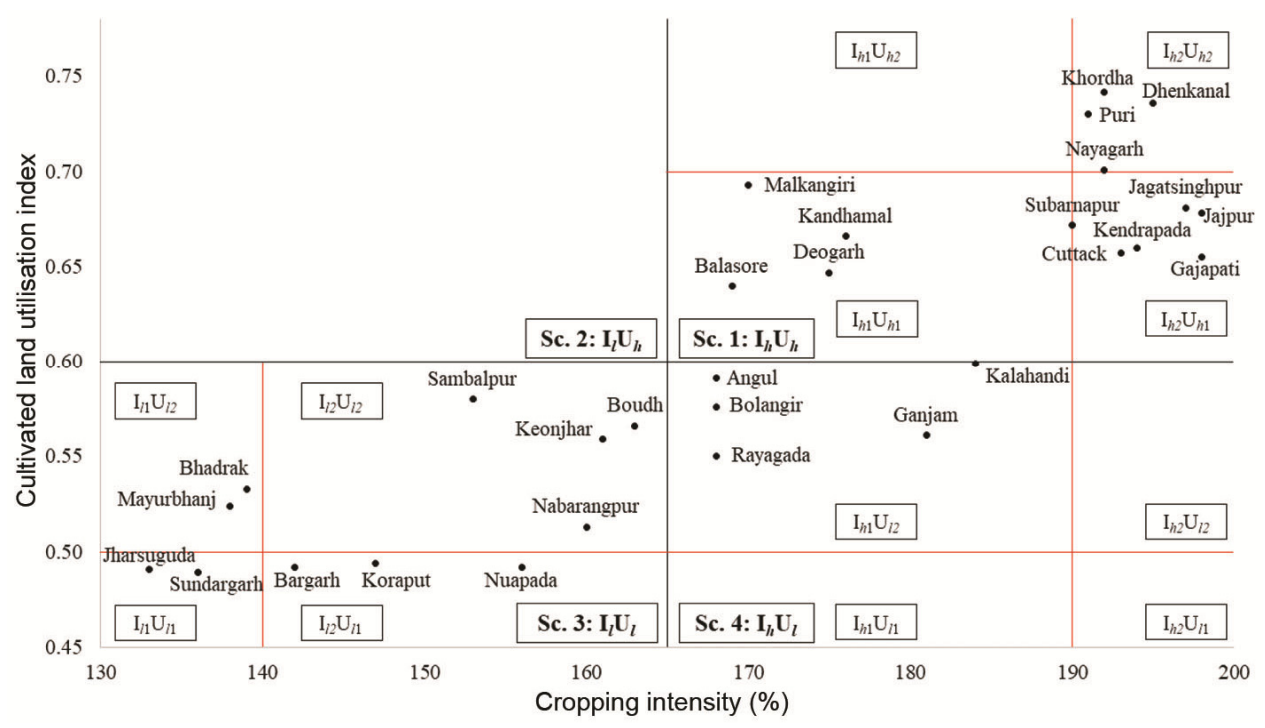

Figure 3. Categorization of districts in Odisha into different scenarios based on cropping intensity and cultivated land utilization index. Sc. indicates scenario number. The short-forms of scenarios and sub-scenarios are according to Table 2 .

crop during rainy season (Table 3). Shifting the waterguzzling rice crop with long-duration varieties of low water requiring crops in a part of the area will improve cropping intensity and CLUI in these districts.

\section{Scenario 4: High cropping intensity and low CLUI $\left(I_{h} U_{l}\right)$}

This scenario included five districts, viz. Angul, Bolangir, Rayagada, Kalahandi and Ganjam in which the cropping intensity ranged from 168\% (Angul, Bolangir and Rayagada) to $184 \%$ (Kalahandi), and CLUI ranged from Rayagada (0.550) to Kalahandi (0.559). All the districts of this scenario belonged to $I_{h 1} U_{l 2}$ sub-scenario. Though Angul, Bolangir and Rayagada had the same level of cropping intensity, CLUI values were different in these districts (Figure 3). The comparably higher CLUI in Angul and Kalahandi indicates better utilization of solar energy in these districts. All the districts under this scenario, except Bolangir, had positive water supply-demand balance. In these districts, CLUI can be increased by fully utilizing the cropping window with longer-duration varieties at the same level of cropping intensity. In Bolangir, the water can be diverted more towards growing low water-requiring crops from high water-requiring crops to increase the cropping intensity and CLUI value.

\section{Conclusion}

The scenario-wise classification of districts in Odisha based on cropping intensity and CLUI highlight the districts having the scope of better resource utilization. Growing of longer-duration varieties fitting a cropping window is suggested for improving CLUI at the same level of cropping intensity. For the districts with limited water availability, growing more number of shortduration, low water-requiring crops with conserved water is suggested instead of long-duration crops. In the state, out of 30 districts, 17 had positive water supply-demand balance. In these districts, the estimated potential irrigated area can be brought under cultivation during the dry season. CLUI along with cropping intensity and water availability in a region can identify the scope of improving system productivity and net returns of the farmers. This approach would aid in ensuring successful implementation of the prime objectives of the New Agricultural Policy of Odisha, 2020. Moreover, CLUI is complementary to cropping intensity and should be considered during crop planning. The results of this study would pave the way for further analysis of CLUI in different States of India, and thereby help in the formulation of national strategies for crop diversification and sustainable waterresource development and management.

1. Business Standard, Foodgrain production estimated at 284.95 million tonnes for 2018-19: 4th advance estimates. 19 August 2019; https://www.business-standard.com/article/news-cm/foodgrainproduction-estimated-at-284-95-million-tonnes-for-2018-194thadvance-estimates-119081901206_1.html

2. ICAR-IIWM, Vision 2050-ICAR-IIWM. ICAR-Indian Institute of Water Management, Bhubaneshwar, 2015, p. 21; http://www. iiwm.res.in/pdf/Vision 2050.pdf

3. Brahmanand, P. S. and Ambast, S. K., Study and analysis of negative list of Indian districts for cultivation of water guzzling crops. Status report (internal circulation). ICAR-Indian Institute of Water Management, Bhubaneshwar, 2016, p. 19.

4. Coulibaly, O. and Ouedraogo, A., Correlation of global solar radiation of eight synoptic stations in Burkina Faso based on linear and multiple linear regression methods. J. Solar Energy, 2016, Article ID 7870907; https://doi.org/10.1155/2016/7870907. 
5. Qian, C., Impact of land use/land cover change on changes in surface solar radiation in eastern China since the reform and opening up. Theoret. Appl. Climatol., 2014, 123, 131-139.

6. Haque, S., Impact of irrigation on cropping intensity and potentiality of groundwater in Murshidabad district of West Bengal, India. Int. J. Ecosyst., 2015, 5(3A), 55-64.

7. Sujatha, B., Photosynthesis. In Plant Biology and Biotechnology (eds Bahadur, B. et al.), 2015, pp. 569-591; ISBN: 978-81-3222285-9.

8. Keisecker, J., Baruch-Mordo, S., Heiner, M., Negandhi, D., Oakleaf, J., Kennedy, C. and Chauhan, P., Renewable energy and land use in India: a vision to facilitate sustainable development. MDPI Sustain., 2019, 12(281), 1-14.

9. Chuang, F. T., An analysis of change of Taiwan's cultivated land utilisation for recent years. Joint Commission on Rural Reconstruction Report 21 Rural and Land Economics Division, Taipei, Taiwan, 1973.

10. Ray, S. S., Sood, A., Panigrahy, S. and Parihar, J. S., Derivation of indices using remote sensing data to evaluate cropping systems. J. Indian Soc. Remote Sensing, 2005, 33, 475.

11. Goswami, J., Sarma, K. K., Handique, B. K., Das, R., Rahman, N. and Raju, P. L. N., Study of cropping system in Morigaon district of Assam using geospatial technique. Int. J. Adv. Remote Sensing, GIS Geogr., 2017, 5(1), 53-59.

12. Government of Odisha, Odisha Agricultural Statistics 2013-14, Directorate of Agriculture and Food Production, 2015, p. 156.

13. Ambast, S. K., Panda, R. K., Sethi, R. R. and Brahmanand, P. S., State irrigation plan of Odisha (Pradhan Mantri Krishi Sinchayee Yojana). Final report submitted to Government of Odisha, 2019, p. 138.

14. Guidelines for improving water use efficiency in irrigation, domestic and industrial sectors. Performance overview and management improvement organization, Central Water Commission, New Delhi, 2014, p. 24.

15. Singandhupe, R. B. and Sethi, R. R., Groundwater resources, its mining and crop planning in Orissa, India. Int. J. Sci. Res. Publ., 2016, 6(11), 26-32.

16. Ali, M. H. and Mubarak, S., Effective rainfall calculation methods for field crops: an overview, analysis, and new formulation. Asian Res. J. Agric., 2017, 7(1), 1-12.

17. Guhathakurta, P., Kulkarni, D., Khedikar, S., Menon, P., Prasad, A. K., Sable, S. T. and Advani, S. C., Observed rainfall variability and changes over Odisha state. Meteorology Monograph No.: ESSO/IMD/HS/Rainfall Variability, India Meteorology Department, Pune, 2020, vol. 20, p. 44.

18. Srivastava, R. C., Singandhupe, R. B. and Mohanty, R. K., Integrated farming approach for runoff recycling systems in humid plateau areas of eastern India. Agric. Water Manage., 2004, 64, $197-212$.
19. Sahu, R. K., Katre, P. and Tripathi, M. P., Alleviation of drought through water harvesting in Chhattisgarh. In Watershed Management (eds Singh, V. P. and Yadav, R. N.), Proceedings of the International Conference on Water and Environment, Bhopal, 1518 December 2003.

20. Rathore, A. L., Pal, A. R., Sahu, R. K. and Chaudhary, J. L., On farm rainwater and crop management for improving productivity of rainfed areas. Agric. Water Manage., 1996, 31, 253-267.

21. Rathore, A. L. and Pal, A. R., Influence of soil drainage on productivity of soybean and peanut grown in a vertisol. Paper presented at the symposium on a sustainable Crop Production in Madhya Pradesh, Raipur Chapter of the Indian Society of Agronomy, at College of Agriculture, Raipur, 23 December 1994.

22. Pal, A. R., Rathore, A. L. and Pandey, V. K., Rainwater storage system for improving riceland productivity, opportunities and challenges for eastern India. Paper presented at the International Conference on Water and Environment held in Bhopal, 15-18 December 2003.

23. Singandhupe, R. B., Sensitivity analysis of reference evapotranspiration $\left(\mathrm{ET}_{0}\right)$ models for irrigation requirement of crops and impact of irrigation on climate changes in semi-arid of India. $A d v$. Res., 2017, 11(6), 1-16.

24. Shukla, J. and Mintz, Y., Influence of land-surface evapotranspiration on the earth's climate. Science, 1982, 215, 1498-1501.

25. Segal, M., Pan, Z. and Turner, R. E., On the potential impact of irrigated areas in North America on summer rainfall caused by large-scale systems. J. Appl. Meteorol., 1998, 37, 325-331.

26. Roy, S. B. and Avissar, R., Impact of land use/land cover change on regional hydrometeorology in Amazonia. J. Geophys. Res., 2002, 107, 4.1-4.12.

27. Singandhupe, R. B., Rao, G. G. S. N., Patil, N. G. and Brahmanand, P. S., Fertigation studies and irrigation system in tomato (Lycopercon eskulentus L.). Eur. J. Agron., 2003, 19, 327-340.

28. Antony, E. and Singandhupe, R. B., Impact of drip and surface irrigation on growth, yield and WUE of capsicum (Capsicum annum L.). Agric. Water Manage., 2004, 65, 121-132.

29. Behera, M. S., Mahapatra, P. K., Singandhupe, R. B. and Kannan, K., Fertigation studies in Japanese mint (Mentha arvensis L.) under humid climate in Odisha, India. Afr. J. Agric. Res., 2015, 10(11), 1020-1030.

30. Singandhupe, R. B., Bankar, M. C., Anand, P. S. B. and Patil, N. G., Drip irrigated sugarcane in western India. Arch. Agron. Soil Sci., 2008, 54(6), 629-649.

Received 22 November 2020; accepted 7 December 2020

doi: $10.18520 / \mathrm{cs} / \mathrm{v} 120 / \mathrm{i} 7 / 1217-1224$ 